\title{
The Comparison of Photocatalytic Degradation and Decolorization Processes of Dyeing Effluents
}

\author{
Ewa Adamek, ${ }^{1}$ Wojciech Baran,, Justyna Ziemiańska, ${ }^{2}$ and Andrzej Sobczak ${ }^{1,2}$ \\ ${ }^{1}$ Department of General and Analytical Chemistry, Medical University of Silesia, Jagiellońska 4, 41-200 Sosnowiec, Poland \\ ${ }^{2}$ Institute of Occupational Medicine and Environmental Health, Kościelna 13, 41-200 Sosnowiec, Poland \\ Correspondence should be addressed to Ewa Adamek; ewa.adamek11@wp.pl
}

Received 18 September 2012; Revised 13 December 2012; Accepted 19 December 2012

Academic Editor: Leonardo Palmisano

Copyright (c) 2013 Ewa Adamek et al. This is an open access article distributed under the Creative Commons Attribution License, which permits unrestricted use, distribution, and reproduction in any medium, provided the original work is properly cited.

\begin{abstract}
Treatment of dye effluents resulting from the industrial scale dyeing of cotton, polyacrylic fibres, leather, and flax fabrics by photocatalytic methods was investigated. Photocatalytic processes were initiated by UV-a light $\left(\lambda_{\max } 366 \mathrm{~nm}\right)$ and were conducted in the presence of $\mathrm{TiO}_{2}, \mathrm{TiO}_{2} / \mathrm{FeCl}_{3}$, or $\mathrm{FeCl}_{3}$ as photocatalysts. It was found that the photocatalytic process carried out with $\mathrm{TiO}_{2}$ and $\mathrm{TiO}_{2} / \mathrm{FeCl}_{3}$ was the most effective method for decolorization of textile dyeing effluents and degradation of dyes, except for effluents containing very high concentrations of stable azo dyes. During the photocatalytic degradation of anionic dyes, a mixture of $\mathrm{TiO}_{2} / \mathrm{FeCl}_{3}$ was more effective, while in the case of cationic dyes, more suitable seems to be $\mathrm{TiO}_{2}$ alone.
\end{abstract}

\section{Introduction}

The textile industry is recognized as one of a major polluting industry which generates large quantities of wastewater [1]. It is estimated that the annual market for dyes is more than $7 \times 10^{5}$ tonnes per year, and about $10 \%-15 \%$ of the world dye production is lost during the dyeing process and released into the environment $[2,3]$. The conventional, biological methods widely used in recent years for the treatment of textile effluent containing synthetic stable dyes can often be ineffective [4]. As a result, colored textile effluents containing mixtures of heavy metals, auxiliaries, and recalcitrant materials can be released into the environment. This and the presence of suspended solids and sediments can negatively affect the aquatic life due to the toxicity of these compounds, a depletion of transparency and dissolved oxygen in water [5]. High level of decolorization of dyeing wastewater is achieved using various physicochemical methods, for example, microfiltration, precipitation, coagulation, flocculation, or different sorption techniques commonly with activated carbon [6]. Unfortunately, these methods only lead to the separation of dyes and to their physical transfer in the environment, for example, from water or wastewater to another storage place (e.g., to sludge dumps) but not to their degradation [2, 7]. Therefore, in recent years, special attention has been focused on the studies concerning the use of advanced oxidation processes (AOPs) that base on the production of highly reactive oxygen species including hydroxyl radicals $\left(\mathrm{HO}^{\circ}\right)$. AOPs can be an alternative for the treatment of wastewater or effluent containing hardly biodegradable organic compounds because they may lead to the formation of low-molecular-weight carboxylic acids or to complete degradation of pollutants to $\mathrm{CO}_{2}$ and $\mathrm{H}_{2} \mathrm{O}$ [8-10].

The photocatalytic process can be carried out under heterogeneous, for example, $\mathrm{TiO}_{2}[11,12]$ conditions, as follows:

$$
\begin{gathered}
\mathrm{TiO}_{2}(\mathrm{aq})+h v \longrightarrow \mathrm{TiO}_{2}\left(\mathrm{~h}_{\mathrm{VB}}{ }^{+}, \mathrm{e}_{\mathrm{CB}}{ }^{-}\right)(\mathrm{aq}) \\
\mathrm{TiO}_{2}\left(\mathrm{~h}_{\mathrm{VB}}{ }^{+}, \mathrm{e}_{\mathrm{CB}}{ }^{-}\right)(\mathrm{aq})+\mathrm{O}_{2} \longrightarrow \mathrm{HO}^{\bullet}+\mathrm{O}_{2}{ }^{--}+\mathrm{H}^{+}
\end{gathered}
$$

and/or homogeneous conditions, for example, $\mathrm{Fe}^{3+}$ salts $[13$, 14] as follows:

$$
\mathrm{Fe}^{3+}(\mathrm{aq})+h v \longrightarrow \mathrm{Fe}^{2+}(\mathrm{aq})+\mathrm{HO}^{\bullet}+\mathrm{H}^{+}
$$

The properties of $\mathrm{TiO}_{2}$ as a photocatalyst are commonly known and well described in the literature $[11,15]$. There have been numerous studies on the removal of organic pollutants including dyes from wastewater on the photoirradiated $\mathrm{TiO}_{2}$ 
surface [16-19]. The photocatalytic degradation of pollutants in the presence of $\mathrm{Fe}(\mathrm{III})$ salts has been also presented in the literature [20-22], but there are only few papers describing photocatalytic properties of $\mathrm{TiO}_{2} / \mathrm{FeCl}_{3}$ mixture [23-25]. It was found that a combination of $\mathrm{Fe}^{3+}$ ions and $\mathrm{TiO}_{2}$ in suspension showed a positive synergistic effect accelerating the photodegradation of organic pollutants [24, 25]. However, none of these papers related to the degradation of azo dyes in real wastewaters.

Most of the experiments were conducted in artificial systems with the use of aqueous solutions (often distilled water) that do not mimic the conditions like in real wastewater. Meanwhile, real dyes effluents commonly contain unused dyes, inorganic ions, and other organic substances that can significantly slow down the photocatalytic degradation efficiency of contaminants. So far, there are some papers and reports concerning treatment of real dye wastewater using photocatalytic processes [26-29], but they demand more profound investigations. The main objective of the study was to compare the efficiency of photodegradation and decolorization processes carried out in the presence of $\mathrm{TiO}_{2}$ and $\mathrm{FeCl}_{3}$ as well as in the mixture of $\mathrm{TiO}_{2} / \mathrm{FeCl}_{3}$ during the treatment of raw real effluents including azodyes. We intended to test four types of wastewaters from large textile factory, industrial tannery, and two from small manufacturies.

\section{Experimental}

2.1. Characteristics of the Used Effluents. The used raw effluents (without dilution and pretreatment) were obtained from the industrial scale dyeing of cotton (WCot), polyacrylic fibers (WPac), leathers (WLeat), and flax fabrics (WFlax). They contained auxiliary substances used during the dyeing process and also, in the case of WLeat, municipal wastes and tannins. Physical and chemical characteristics of effluents are presented in Table 1. A criterion for choice of wastewater was the presence of azo dyes resistant to biological degradation. The analyzed wastes differed due to the type of used technology and the type of dyed materials. Dyes contained in wastewaters were stable and did not undergo biodegradation during the storage by a period of 28 days in room temperature. To remove sulfides wastes, were intensively aerated for $30 \mathrm{~min}$, before commencement of the experiments.

2.2. Characteristics of Photocatalysts. Titanium (IV) dioxide powder $\left(\mathrm{TiO}_{2}\right)$ used as the photocatalyst was obtained from Riedel de Haën (anatase 100\%, a mean BET surface area of 9$11 \mathrm{~m}^{2} \mathrm{~g}^{-1}$, residues on filter $>40 \mu \mathrm{m}$ after dispersion in water $<0.02 \%, \mathrm{pH}_{\mathrm{pzc}}=3.00 \pm 0.05$ ) [30]. During preliminary studies, it was found that during decolorization of cationic dyes solutions this catalyst was more effective than $\mathrm{TiO}_{2}-\mathrm{P} 25$. Moreover, its mixture with $\mathrm{FeCl}_{3}$ was more effective during decolorization of anionic dyes in distilled water than that with $\mathrm{TiO}_{2}-\mathrm{P} 25$ [23].

The iron (III) chloride $\left(\mathrm{FeCl}_{3} \cdot 6 \mathrm{H}_{2} \mathrm{O}\right)$ and all other chemicals used for analysis were purchased from $\mathrm{POCH}$ (Poland) and were of analytical grade. Freshly prepared

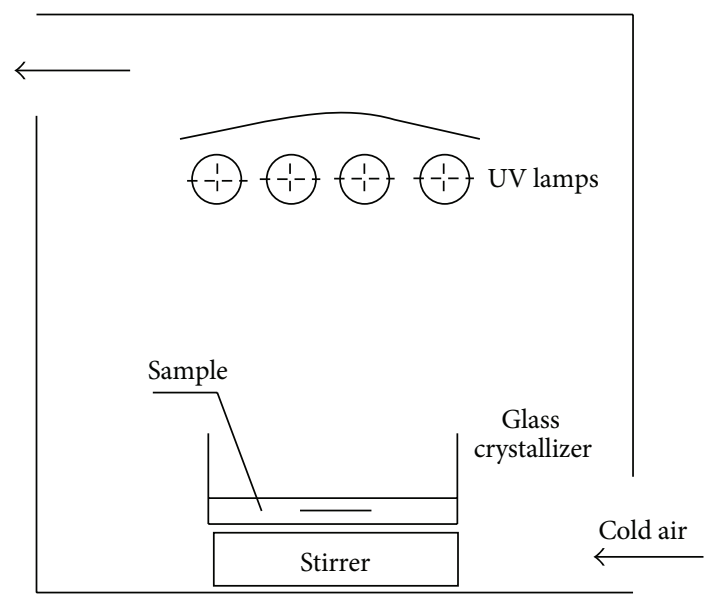

FIGURE 1: The scheme of test stand.

$\mathrm{FeCl}_{3}$ stock solution in distilled water $\left(1.0 \mathrm{~mol} \mathrm{~L}^{-1}\right)$ or solid $\mathrm{TiO}_{2}\left(2.5 \mathrm{~g} \mathrm{~L}^{-1}\right)$ or a mixture of $\mathrm{TiO}_{2}\left(2.5 \mathrm{~g} \mathrm{~L}^{-1}\right)$ and $\mathrm{FeCl}_{3}$ $\left(1.0 \mathrm{~mol} \mathrm{~L}^{-1}\right)$ was added to $100 \mathrm{~mL}$ of effluents. The concentrations of $\mathrm{TiO}_{2}$ and $\mathrm{FeCl}_{3}$ were established as optimal, based on preliminary published experiments [23] and according to the unpublished data. The used amount of $\mathrm{FeCl}_{3}$ solution was determined experimentally in such manner that after its addition to effluent, the $\mathrm{pH}$ of sample was about 3 (Table 2).

2.3. Irradiation. Before irradiation, the samples with $\mathrm{TiO}_{2}$ were stirred magnetically for $20 \mathrm{~min}$ in the dark to ensure the complete equilibrium between adsorption/desorption processes of organic compounds on the photocatalyst surface.

In all experiments, five open glass crystallizers (volume: $500 \mathrm{~mL}$, the exposed surface: $102 \mathrm{~cm}^{2}$ ) containing $100 \mathrm{~mL}$ of effluent with catalysts were irradiated by four UV-a lamps (Philips TL-40 W/05 at $\lambda_{\max } 366 \mathrm{~nm}$ ) in order to ensure the steady-state illumination of the entire surface of crystallizers. The intensity of UV-a and VIS radiation measured by the Quantum-foto radiometer DO9721 (Delta OHM) was 5.35 and $12.0 \mathrm{~W} \mathrm{~m}^{-2}$, respectively. The scheme of the test stand is shown in Figure 1.

During the whole experiment, all samples were intensively stirred at a constant speed and had a free contact with atmospheric air but were not aerated additionally. During irradiation, the concentration of dissolved oxygen in the samples was $>80 \%$. The initial temperature of samples was $20 \pm 2^{\circ} \mathrm{C}$. The $\mathrm{pH}$ and concentration of oxygen dissolved in irradiated samples were measured by multimeter HD22569.2 (Delta OHM).

2.4. The Analysis. After the appropriate irradiation time (0$300 \mathrm{~min}$ ), samples were centrifuged for $30 \mathrm{~min}$ at $4000 \mathrm{rpm}$ at room temperature (MPW-360 centrifuge, Poland). The UV-VIS spectra of the irradiated effluents in the range from 200 to $800 \mathrm{~nm}$ were recorded by spectrophotometer (Secoman S-750) in $1 \mathrm{~cm}$ quartz cuvettes. The concentrations of dyes in samples were determined using HPLC method (HPLC D-7000 Merck, detector UV VIS Hitachi-L 7400, column: Supelcosil LC- $18.5 \mu \mathrm{m}, 250 \mathrm{~mm} \times 4.6 \mathrm{~mm}$, mobile 


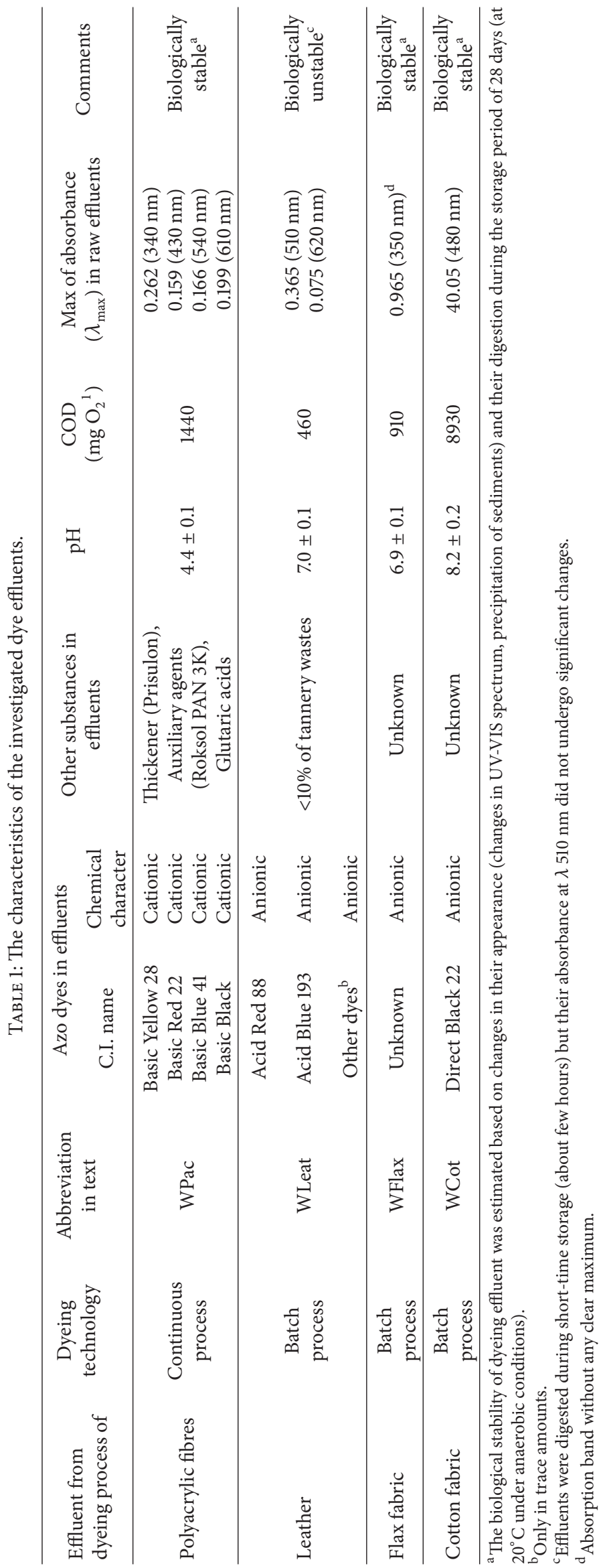


TABLE 2: The concentrations of reagents used and experimental conditions.

\begin{tabular}{ccccc}
\hline Effluent & $\begin{array}{c}\mathrm{FeCl}_{3} \\
\left(\mathrm{mmol} \mathrm{L}^{-1}\right)\end{array}$ & $\begin{array}{c}\mathrm{TiO}_{2} \\
\left(\mathrm{~g} \mathrm{~L}^{-1}\right)\end{array}$ & $\mathrm{pH}^{\mathrm{a}}$ & $\begin{array}{c}\text { Concentration of Fe(III) } \\
\text { in irradiated effluent } \\
\left(\mathrm{mmol} \mathrm{L}^{-1}\right)\end{array}$ \\
\hline WPac & 1.0 & - & 3.3 & n.d. $^{\mathrm{b}}$ \\
& - & 2.5 & 4.4 & - \\
WLeat & 1.0 & 2.5 & 3.6 & n.d. $^{\mathrm{b}}$ \\
\hline \multirow{4}{*}{ WFlax } & - & - & 3.1 & 0.02 \\
& 1.5 & 2.5 & 7.0 & - \\
\hline \multirow{3}{*}{ WCot } & 1.5 & - & 3.2 & 0.04 \\
& 1.5 & 2.5 & 6.3 & 0.30 \\
& 13 & - & 3.5 & - \\
\hline
\end{tabular}

${ }^{a}$ At the beginning of UV-a irradiation, ${ }^{b}$ no data.

phase: $10 \mathrm{mM} \mathrm{K}_{2} \mathrm{HPO}_{4}$ at $\mathrm{pH} 9.0 / \mathrm{CH}_{3} \mathrm{CN}$, in the ratio $95: 5$ for WLeat, WFlax, and WCot and $20 \mathrm{mM}$ acetic buffer at $\mathrm{pH} 4.8 / \mathrm{CH}_{3} \mathrm{CN}$, in the ratio $6: 4$ for WPac, resp.). Before HPLC analysis, water-insoluble sediments containing Fe(III) compounds with components of effluents were dissolved after adding the concentrated $\mathrm{HCl}$ (to $\mathrm{pH}<1$ ) or $\mathrm{NaOH}$ (to $\mathrm{pH} \approx 13$ ). The chemical oxygen demand (COD) was estimated by titration method (US EPA 410.1-3) [31]. Additionally, dyes degradation in effluents was determined spectrophotometrically based on the decrease of peaks on characteristic wavelengths at $\lambda_{\max }$ (Table 3 ). The analysis of the intermediate products was not performed because it was not the main aim of this study.

2.5. Results Elaboration. The degree of degradation for particular dyes $\left(X_{i}\right)$ was calculated based on the results obtained from HPLC method according to the following equation:

$$
X_{i}=100 \cdot\left(1-\frac{S_{i}}{S_{o}}\right),
$$

where $S_{i}$ is the peak area corresponding to the undecomposed dye after the irradiation of wastewater, and $S_{o}$ is the peak area corresponding to the dye before the irradiation.

Its means that any transformation of dye occurring as a result of the irradiation in the presence of a photocatalyst was considered as its degradation. In this sense, the dye degradation does not mean its mineralization. In the case of azo dyes, their degradation will mean their decomposition to lower and simpler organic compounds by breaking of azo bonds.

The reaction rate constant for dyes photodegradation $\left(k_{X_{i}}\right)$ was determined as for the pseudo first-order reaction, that is, as the slope of the following linear dependency:

$$
\ln \frac{S_{o}}{S_{i}}=f(t) .
$$

Reduction of color in the physical process only $(Y)$ was calculated based on the absorbance of raw, centrifuged effluents $\left(A_{o}\right)$ and the absorbance of the same effluents but after addition of the catalyst $\left(\mathrm{TiO}_{2}\right.$ and/or $\left.\mathrm{FeCl}_{3}\right)$ and after centrifugation $\left(A_{Y}\right)$ as follows:

$$
Y=100 \cdot\left(1-\frac{A_{Y}}{A_{o}}\right) .
$$

In these cases, the photocatalyst-containing samples were not exposed to irradiation; that is, the photocatalytic processes did not proceed in them but only adsorption, coagulation, flocculation, and precipitation. In some samples, the addition of $\mathrm{FeCl}_{3}$ resulted in an increased intensity of color in effluents, so the $Y$ value was negative.

Reduction of color in the photocatalytic process only $(Z)$ was determined based on the absorbance of centrifuged effluents with catalysts $\left(\mathrm{TiO}_{2}\right.$ and/or $\left.\mathrm{FeCl}_{3}\right)\left(A_{Y}\right)$ and the absorbance of the same effluents but after their irradiation with these catalysts $\left(A_{z}\right)$ as follows:

$$
Z=100 \cdot\left(1-\frac{A_{Z}}{A_{Y}}\right) .
$$

In these cases, the reason of effluents decoloration may be the photocatalytic process only.

The rate constant for dyes photodecolorization $\left(k_{Z i}\right)$ was determined as the slope of the following linear function:

$$
\ln \frac{A_{Y}}{A_{Z}}=f(t) .
$$

Total decolorization of effluents (Total) was calculated using the following formula:

$$
\text { Total }=100 \cdot\left(1-\frac{A_{z}}{A_{o}}\right) .
$$

COD removal $\left(R_{\mathrm{COD}}\right)$ was determined based on the following equation:

$$
R_{\mathrm{COD}}=100 \cdot\left(1-\frac{\mathrm{COD}_{300}}{\mathrm{COD}_{\mathrm{o}}}\right),
$$

where $\mathrm{COD}_{\mathrm{o}}$ was determined in raw effluents and $\mathrm{COD}_{300}$ was determined in the same effluents but after 300 min of UVa irradiation in the presence of $\mathrm{TiO}_{2}$ and/or $\mathrm{FeCl}_{3}$.

\section{Results and Discussion}

3.1. Effect of $\mathrm{FeCl}_{3}$. The high photocatalytic activity of $\mathrm{Fe}(\mathrm{III})$ salts in model solutions is related to their partial hydrolysis products, namely, $\mathrm{Fe}(\mathrm{OH})^{2+}$ ions, that show the maximum photocatalytic activity in the $\mathrm{pH} \approx 3$ [13]. The addition of $\mathrm{FeCl}_{3}$ to effluent samples caused precipitation of waterinsoluble matter (with the exception of WPac), and almost total their decolorization (Table 3). However, the UV-a irradiation for $60 \mathrm{~min}$ did not cause significant changes in UV-Vis spectra and in HPLC chromatograms for any of the analyzed samples. Additionally, after a prolonged irradiation time to 


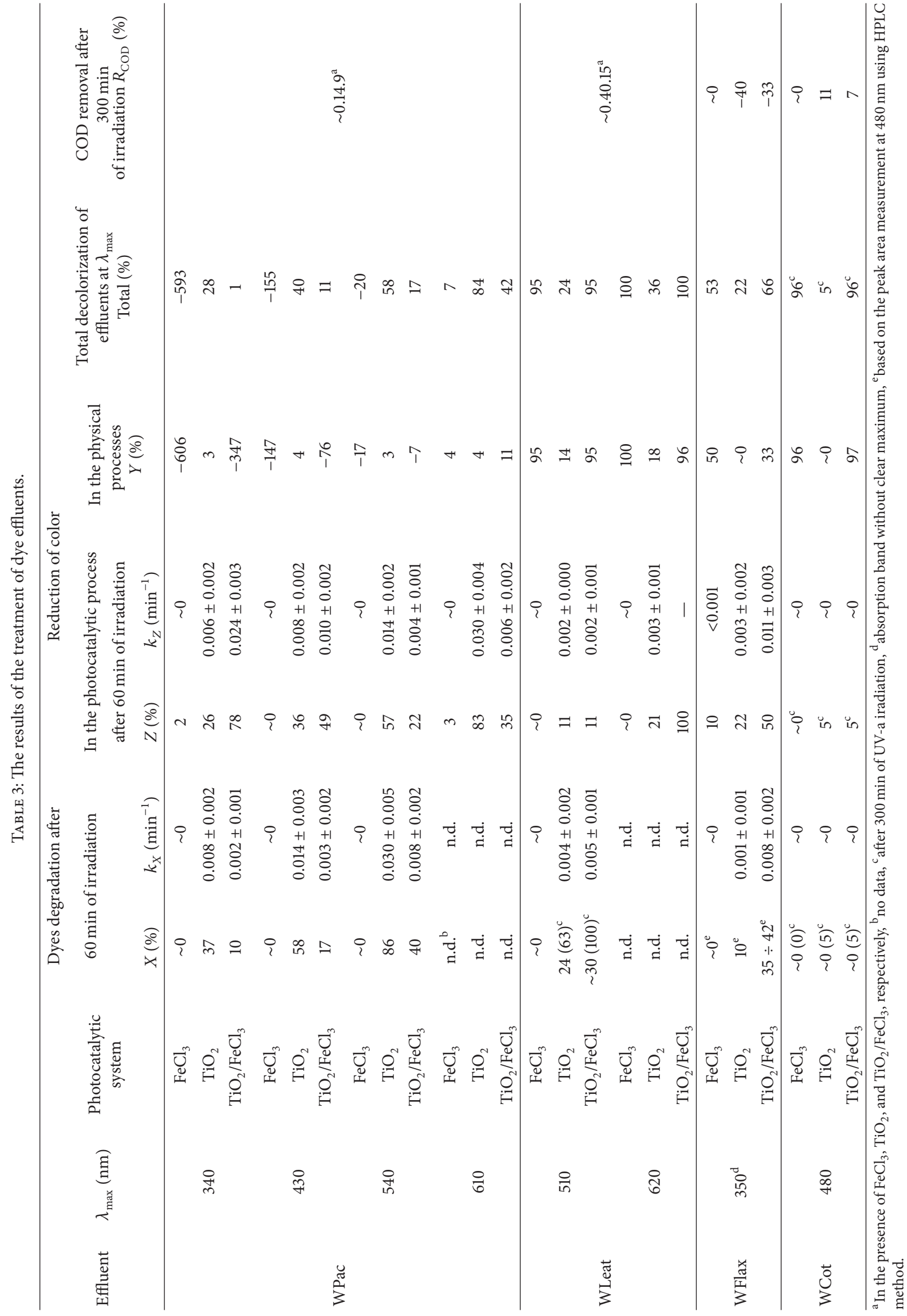


$300 \mathrm{~min}$, no significant changes in chromatograms and in COD values were observed.

After the dissolution of water insoluble Fe-organic complexes, chromatograms of samples (before and after UV irradiation) remained practically unchanged. This observation indicates that during UV-a irradiation of effluents with Fe(III) salt only, dyes did not undergo the photocatalytic degradation. The use of $\mathrm{FeCl}_{3}$ and probably also other $\mathrm{Fe}$ (III) salts as a catalyst in the photocatalytic treatment process of dye effluents is completely ineffective (after $60 \mathrm{~min}$ of irradiation the photodegradation efficiency was in the range of $0 \%)$. Therefore, under model conditions, model $\mathrm{Fe}(\mathrm{OH})^{2+}$ ions can have photocatalytic activity at $\mathrm{pH} 3$, but in real wastewater samples, for example, in dye effluents, they may act as a coagulant only.

3.2. Effect of $\mathrm{TiO}_{2}$. After centrifugation of nonirradiated samples with $\mathrm{TiO}_{2}$, no significant changes in UV-VIS spectra (Figure 2) and HPLC chromatograms were observed. Simultaneously, in all effluent samples the photocatalyst was coagulated only in a negligible level.

As can be seen from the UV-VIS spectra shown in Figure 2(a), after UV-a irradiation of samples containing cationic dyes (WPac) with $\mathrm{TiO}_{2}$ for $60 \mathrm{~min}$, the effluent underwent high decolorization resulting in a completely colorless effluent. The disappearance of the absorption bands $\left(\lambda_{\max }\right.$ at $340,430,520$, and $\left.610 \mathrm{~nm}\right)$ suggests that the chromophore groups, responsible for color, progressively break down during UV-a irradiation. Therefore, in the case of cationic dyes, the effluent decolorization was almost exclusively the result of the photocatalytic process and only in a small degree due to physical processes such as precipitation, coagulation, or sorption. The degradation efficiency of cationic dyes was in the range of $37 \%-86 \%$, but the COD removal was low even after 300 min of irradiation and was only $14 \%$ (Table 3 ).

The decolorization (a decrease in absorbance) was also observed in WLeat and WFlax effluents containing anionic dyes (Figures 2(b) and 2(c)). After irradiation of samples in the presence of $\mathrm{TiO}_{2}$, a decrease of absorbance at 510 and $620 \mathrm{~nm}$ for WLeat and a decrease of a continuous band (without any distinct maximum) for WFlax were observed. In the case of effluent resulting from dyeing of leather (WLeat), decolorization was the result of both the photodegradation and the physical processes. The maximum degradation degree of one of the dyes, namely, Acid Red 88, was 63\% after 300 min of UV-a irradiation (Table 3).

On the other hand, WFlax effluents irradiated for $60 \mathrm{~min}$ with $\mathrm{TiO}_{2}$ exhibited lower dyes degradation, in the range of $10 \%$. The UV-a irradiation for 300 min caused a decrease in COD value about $40 \%$ in WLeat effluents and, on the contrary, an increase in COD value of $40 \%$ in WFlax (Table 3).

As shown in Figure 2(d), in effluents from cotton dyeing processes (WCot), decolorization and changes in HPLC chromatograms practically were not observed. The degradation degree of dye was $<5 \%$ even after $300 \mathrm{~min} U \mathrm{UV}$-a irradiation. In these samples, the degradation efficiency was very low probably because of less transmission of UV-a light through the black effluents. Additionally, WCot samples containing high concentration of dye (Direct Black 22) had the highest COD, over $8900 \mathrm{mg} \mathrm{O}_{2} \mathrm{~L}^{-1}$. Therefore, after $300 \mathrm{~min}$ of irradiation, the COD removal was about 11\% (Table 3).

The photodegradation of compounds during/in heterogeneous photocatalysis depends among other factors on the chemical properties of substrates and their adsorption ability onto the photocatalyst surface [11]. In accordance to heterogeneous catalysis theory (Langmuir- Himselwood model), the increase in adsorption of dyes causes the increase in the photocatalytic degradation rate. Additionally, $\mathrm{TiO}_{2}$ shows an amphoteric character and its photocatalytic activity depends also on the $\mathrm{pH}$ of samples. In the case of the investigated $\mathrm{TiO}_{2}$ (pure anatase), the determined $\mathrm{pH}$ value of the point of zero charge $\left(\mathrm{pH}_{\mathrm{pzc}}\right)$ was 3.00. In the used dyes effluents, the $\mathrm{pHs}$ were always higher than $\mathrm{pH}_{\mathrm{pzc}}$ and therefore $\mathrm{TiO}_{2}$ surface should be negatively charged as follows:

$$
\mathrm{Ti}-\mathrm{OH}_{2}+\stackrel{\mathrm{pH}<\mathrm{pH}_{\mathrm{pzc}}}{\Longleftrightarrow} \mathrm{Ti}-\mathrm{OH} \stackrel{\mathrm{pH}>\mathrm{pH}_{\mathrm{pzc}}}{\Longleftrightarrow} \mathrm{TiO}^{-}
$$

This fact may explain the higher adsorption and higher photodegradation ability of cationic dyes (in WPac effluents) and lower adsorption of anionic dyes (WCot and WFlax) onto the $\mathrm{TiO}_{2}$ surface under the studied conditions. However, it does not simply explain high degradation of anionic dyes in WLeat effluents. The adsorption process onto $\mathrm{TiO}_{2}$ surface under UV-irradiation conditions is complex and some differences in an adsorption capacity of particles may occur. Probably, a higher removal of COD in WLeat can be attributed to the adsorption of increased amounts of undissociated particles (e.g., anionic dyes with organic or inorganic ions) on the $\mathrm{TiO}_{2}$ surface. Additionally, the organic compounds in WLeat, that is, dyes, surfactant agents, and auxiliaries, were rather photo labile and they were easily transformed to less stable organics (byproducts).

3.3. Effect of $\mathrm{TiO}_{2} / \mathrm{FeCl}_{3}$. As shown in Figure 3, the addition of $\mathrm{TiO}_{2} / \mathrm{FeCl}_{3}$ mixture to nonirradiated effluents caused a significant coagulation and decolorization of all samples. Therefore, in these processes, Fe salts could play a role of coagulant. However, UV-a irradiation of such samples resulted in their decolorization (Figure 3, Table 3) and this may indicate its role as a photosensitizer.

It was found that the photocatalytic degradation in effluent containing cationic dyes (WPac) was less effective in the mixture of $\mathrm{TiO}_{2} / \mathrm{FeCl}_{3}$ than in the presence of $\mathrm{TiO}_{2}$ alone (Table 3). After $60 \mathrm{~min}$ of UV-a irradiation, the degradation efficiency of dyes was in the range $10 \%-40 \%$. Simultaneously, WPac underwent the effective decolorization which can be explained only as the dyes photodegradation (Figure 3(a)). This process was not inhibited by strong coagulation of photocatalysts and by auxiliary substances, contained in these samples. After the addition of $\mathrm{TiO}_{2} / \mathrm{FeCl}_{3}$ but before $\mathrm{UV}$ a irradiation, absorbance in WPac effluent at $\lambda<500 \mathrm{~nm}$ was significantly higher due to the presence of dissolved $\mathrm{Fe}$ (III) compounds (dashed line). The data concerning COD removal indicate that the efficiency of WPac mineralization after 300 min of UV-a irradiation reached only $9 \%$. 


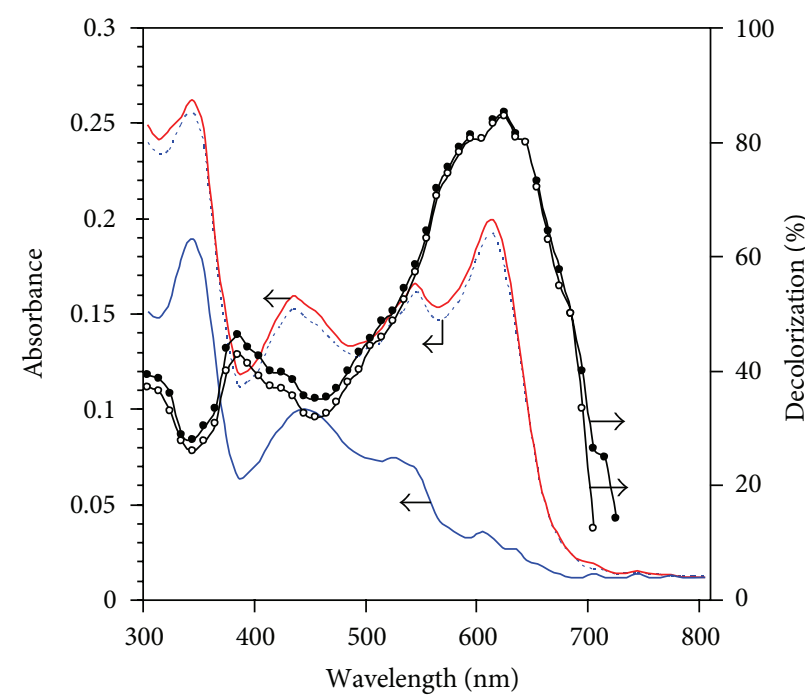

(a)

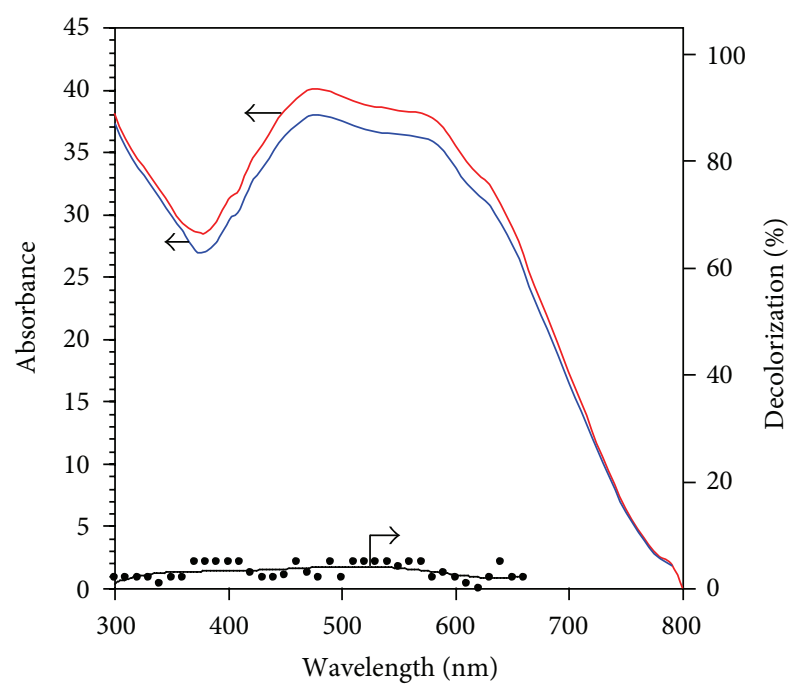

(c)

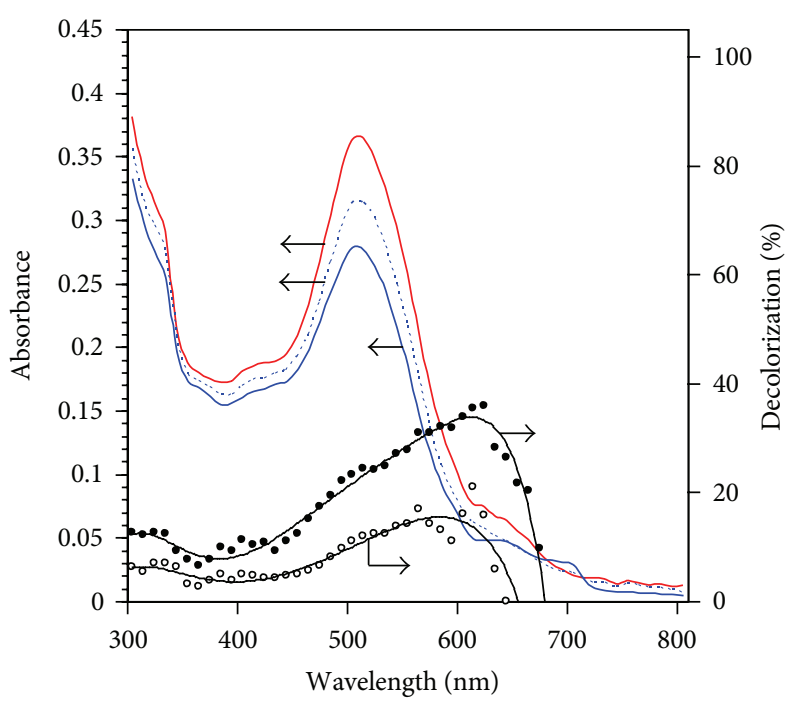

(b)

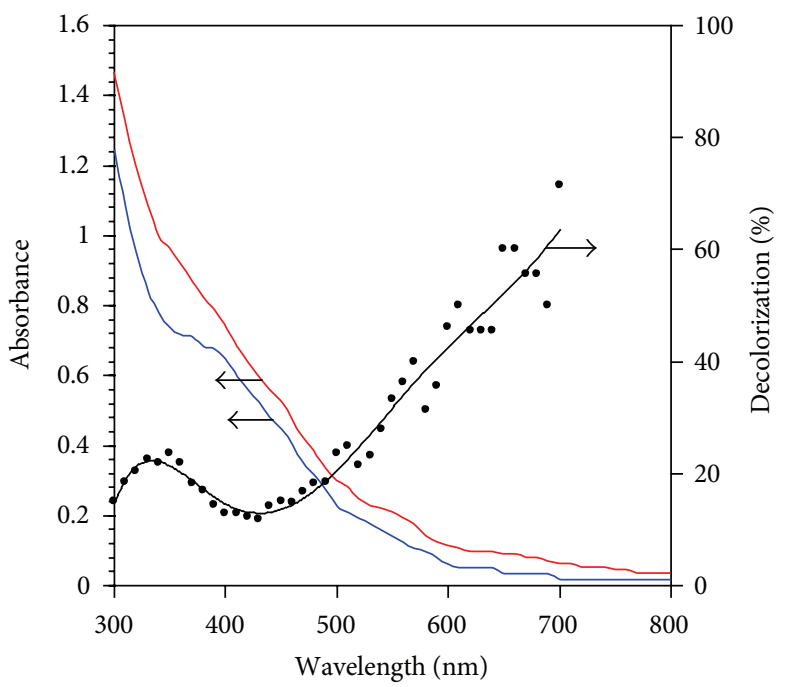

(d)

FIGURE 2: Absorption and decolorization spectra of WPac (a), WLeat (b), WFlax (c), and WCot (d). Solid line (red): initial spectrum of effluent, $A_{o}$; dotted line (blue): effluent with $\mathrm{TiO}_{2}$, without $\mathrm{UV}$-a irradiation, $A_{Y}$; solid line (blue): effluent with $\mathrm{TiO}_{2}$, after UV-a irradiation, $A_{Z} ;(\bullet)$ total decolorization of effluent with $\mathrm{TiO}_{2}\left(2.5 \mathrm{~g} \mathrm{~L}^{-1}\right)$ and after UV-a irradiation; $(\bigcirc)$ decolorization of effluent as a result of the photocatalytic process in the presence of $\mathrm{TiO}_{2}\left(2.5 \mathrm{~g} \mathrm{~L}^{-1}\right)$ and after $\mathrm{UV}$-a irradiation.

On the contrary, effluents containing anionic dyes (WLeat and WFlax) underwent the photocatalytic degradation more effectively in the presence of $\mathrm{TiO}_{2} / \mathrm{FeCl}_{3}$ than in $\mathrm{TiO}_{2}$ alone (Table 3). Upon UV-a irradiation, there were continuous decreases in absorbance all along the spectra meaning the fragmentation of organic structures and the photocatalytic degradation of dyes (Figures 3(b) and 3(c)). As shown in Table 2, the complete removal of Acid Red 88 from WLeat was the result of both direct precipitation and/or adsorption on the photocatalyst surface and photodegradation process. The degradation efficiency of this dye was high and reached even 100\% after 300 min of UV-a irradiation (Table 3). The decolorization of WFlax was caused to a greater extent by the photocatalytic process than coagulation and/or precipitation (Figure 3(c)). The dyes degradation was in the range $35 \%-42 \%$ after 60 min of UV-a irradiation. Removal of COD in WLeat in the presence of $\mathrm{TiO}_{2} / \mathrm{FeCl}_{3}$ was $15 \%$ and was lower than in the presence of $\mathrm{TiO}_{2}$ alone. On the other hand, similarly as during irradiation of WFlax with $\mathrm{TiO}_{2}$ alone, after $300 \mathrm{~min}$ of $\mathrm{UV}-\mathrm{a}$ irradiation with $\mathrm{TiO}_{2} / \mathrm{FeCl}_{3}$ there was not a decrease of COD value but its increase.

In our opinion, an increase in COD removal upon UVa irradiation of WFlax with $\mathrm{TiO}_{2}$ and $\mathrm{TiO}_{2} / \mathrm{FeCl}_{3}$ is only provisional. This effect can be explained by an increase in the concentration of smaller organics molecules formed during the photocatalytic oxidation of dyes and suspended solids. Most of the decomposable compounds are removed in the initial time of this process and the remained part of organic 


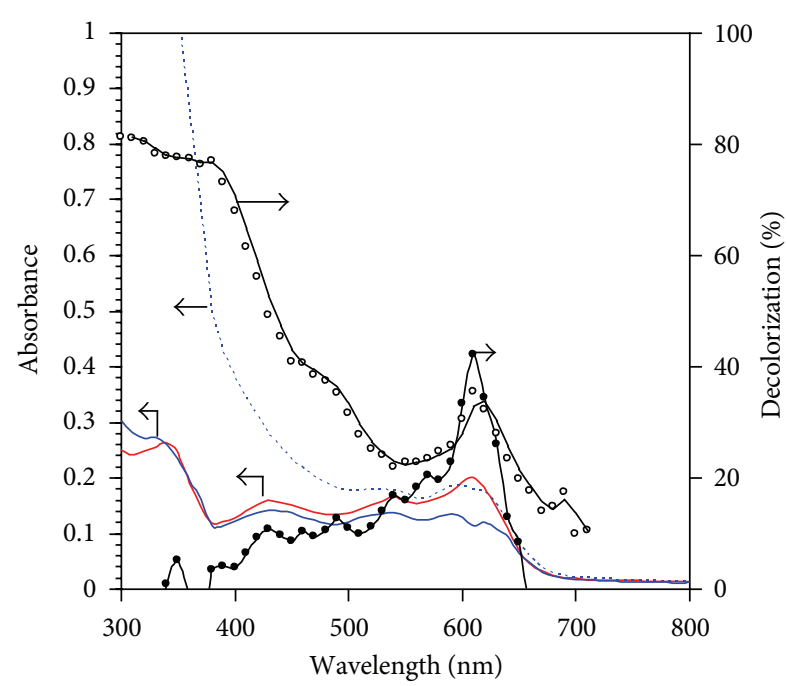

(a)

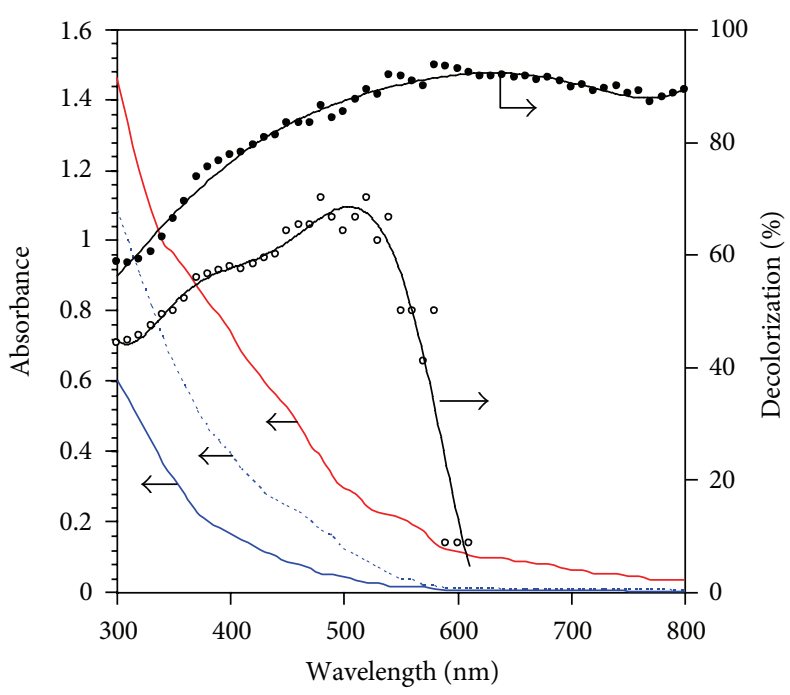

(c)

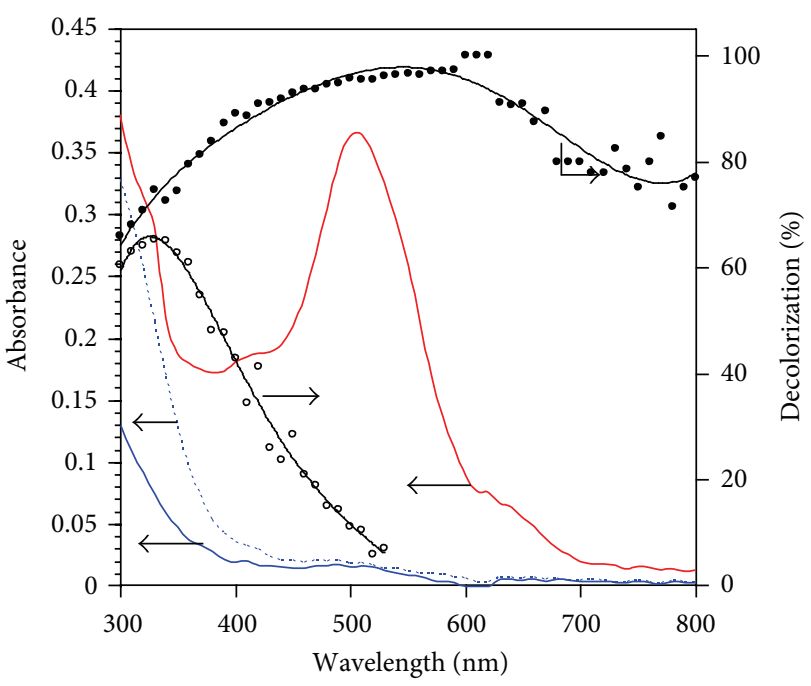

(b)

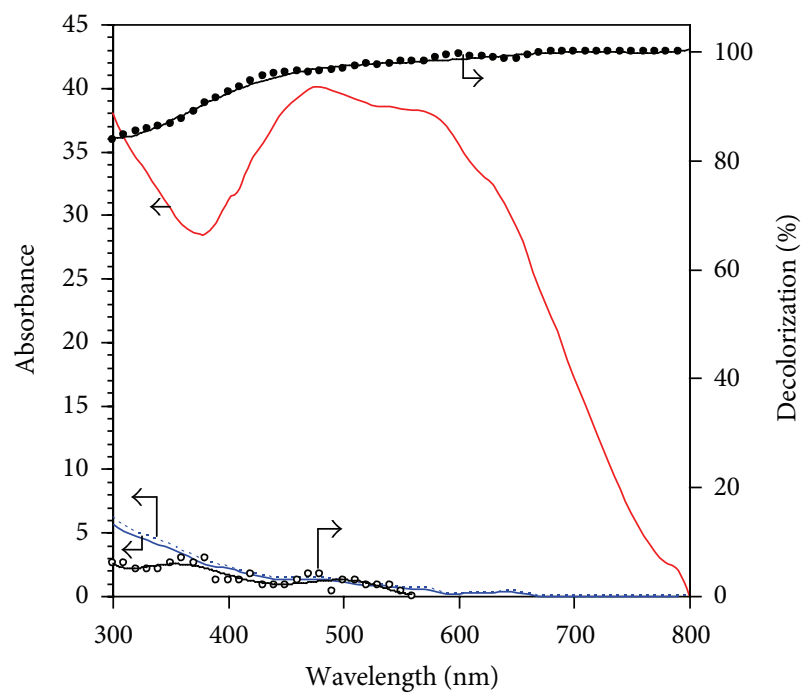

(d)

Figure 3: Absorption and decolorization spectra of WPac (a), WLeat (b), WFlax (c), and WCot (d). Solid line (red): initial spectrum of effluent, $A_{o}$; dotted line (blue): effluent with $\mathrm{TiO}_{2}$ and $\mathrm{FeCl}_{3}$ but without $\mathrm{UV}$-a irradiation, $A_{Y}$; solid line (blue): effluent with $\mathrm{TiO}_{2}$, $\mathrm{FeCl}$ and after UV-a irradiation, $A_{Z} ;(\bullet)$ total decolorization of effluent with $\mathrm{TiO}_{2}\left(2.5 \mathrm{~g} \mathrm{~L}^{-1}\right)$ and $\mathrm{FeCl}_{3}\left(1.0 \mathrm{mmol} \mathrm{L}^{-1}\right)$ and after $\mathrm{UV}$-a irradiation; $(\bigcirc)$ decolorization of effluent as a result of the photocatalytic process in the presence of $\mathrm{TiO}_{2}\left(2.5 \mathrm{~g} \mathrm{~L}^{-1}\right), \mathrm{FeCl}_{3}\left(1.0 \mathrm{mmol} \mathrm{L}^{-1}\right)$, and after $\mathrm{UV}$-a irradiation.

pollutants, for example, lower molecular weight carboxylic acids, aldehydes, and ketones, can be less removable. These byproducts may not be completely mineralized by $\mathrm{K}_{2} \mathrm{Cr}_{2} \mathrm{O}_{7}$ because they are quite resistant and their chemical oxidation can be the rate-limiting step in oxidation processes. Therefore, they require more severe oxidation conditions or a longer time for their conversion. On the other hand, the COD values enable only qualitative rather than quantitative assessment of the mineralization process [32].

After the addition of $\mathrm{TiO}_{2} / \mathrm{FeCl}_{3}$ to WCot, the decolorization was found to be almost $100 \%$ resulting in a completely colorless effluent (Figure 3(d)). However, the removal of Direct Black 22 was the result of its precipitation only and not the photocatalytic process. The efficiency of photocatalytic degradation of this dye after $300 \mathrm{~min}$ of UV-a irradiation was $<5 \%$ (Table 3).

Furthermore, the organic load of WCot effluent irradiated with $\mathrm{TiO}_{2} / \mathrm{FeCl}_{3}$ did not change significantly; the COD removal remained low at a value of about $7 \%$. Taking into account the high chemical stability of dye (Direct Black 22) in WCot as well as its high concentration in effluent, the photocatalytic degradation of WCot in the presence of $\mathrm{TiO}_{2}$ and $\mathrm{TiO}_{2} / \mathrm{FeCl}_{3}$ is not an effective method.

An estimation of the efficiency of the studied photocatalytic systems $\left(\mathrm{TiO}_{2}\right.$ and $\left.\mathrm{TiO}_{2} / \mathrm{FeCl}_{3}\right)$ used during the photocatalytic degradation of real effluents also depends on 
the chemical properties of dyes and on the possibility of formation of coordination compounds with $\mathrm{Fe}^{3+}$ ions.

In the case of effluents containing cationic dyes (WPac), the addition of $\mathrm{Fe}(\mathrm{III})$ salt was unfavorable because the efficiency of photodegradation of these dyes and COD removal were lower than that in the presence of $\mathrm{TiO}_{2}$ only. The explanation of this result can be the change of charge of $\mathrm{TiO}_{2}$ particles (in the presence of $\mathrm{Fe}^{3+}$ ions) that limits the possibility of sorption of the positively charged particles of cationic dyes.

In the case of effluents containing anionic dyes (WLeat and WFlax), the presence of $\mathrm{Fe}^{3+}$ ions had a beneficial effect on the efficiency of photocatalytic degradation of these compounds. The possible explanations may be a formation of photoactive complexes between dyes particles and $\mathrm{Fe}^{3+}$ ions that absorb UV-a irradiation much better than individual molecules of dyes or an adsorption of complexes of dyes with $\mathrm{Fe}^{3+}$ ions on the photocatalyst surface.

The investigated dyes effluents containing also other pollutants, such as fatty acids, sugars, and amino acids which may also be substrates for the photodegradation and can therefore compete with the dyes. Additionally, they may contain inorganic mobile anions, such as $\mathrm{Cl}^{-}, \mathrm{CO}_{3}{ }^{2-}$, $\mathrm{SO}_{4}{ }^{-2}, \mathrm{PO}_{4}{ }^{3-}$, and $\mathrm{NO}_{3}{ }^{-}$, which may significantly affect the distribution of hydroxyl radicals in the following process:

$$
\mathrm{XO}^{n-}+\mathrm{HO}^{\bullet} \longrightarrow \mathrm{XO}^{\cdot(n-1)^{-}}+\mathrm{OH}^{-}
$$

As a result, these anions at high concentrations can decrease the photodegradation that simultaneously occurs between $\mathrm{HO}^{\circ}$ radicals and dyes molecules.

From the viewpoint of COD removal, $\mathrm{TiO}_{2}$ alone was a much more effective photocatalyst than $\mathrm{TiO}_{2} / \mathrm{FeCl}_{3}$. The increase in COD value in WFlax effluent probably was connected with the presence of a very persistent substance(s) that did not undergo the oxidation during the COD determination. On the other hand, the photocatalytic process leads to degradation of these substances and the obtained products are much less chemically resistant. In this aspect, the observed phenomenon is not negative. In our publication [33], we have reported, similar to other authors [34], that the complete photocatalytic degradation of contaminants during the treatment of effluents is still not economically feasible due to high operating costs. Therefore, the reduction of time of photocatalytic process only to the time necessary to initial degradation of nonbiodegradable substances (e.g., azo dyes) towards the most readily biodegradable intermediates is the most reasonable. It is obvious that one single treatment step cannot remove all pollutants contained in dyes effluents. The optimal solution is the combination of different treatment processes, for example, the photocatalytic degradation using sunlight as the source of UV light with a biological process. It may significantly decrease the overall cost of the dye effluents treatment. Additionally, the photocatalytic pretreatment of dyeing effluents can lead to improvement of their biodegradability, for example, initial toxicity induced by photodegradation of textile antraquinone dye to Vibria fisheri progressively decreased during the course of process [35]. In this way, a significant decrease in the overall cost of the treatment of dyes effluents is expected mainly through the combination of several AOPs, for example, the photocatalytic degradation as a pretreatment method with biological processes [36]. An increase of biodegradability of these effluents would facilitate their subsequent biological treatment and an effective removal of undesirable and/or recalcitrant pollutants making the complete mineralization unnecessary.

\section{The Mechanism of Wastewater Decolorization Processes}

The experiments confirmed that $\mathrm{TiO}_{2}$ caused decolorization of wastewater mainly due to photocatalytic process. However, the decolorization of WLeat could be a result of dyes sorption onto $\mathrm{TiO}_{2}$ surface (Table 3).

As previously described, $\mathrm{FeCl}_{3}$ alone could not be the cause of decolorization of wastewater during the photocatalytic process. On the other hand, the addition of $\mathrm{FeCl}_{3}$ accelerated undoubtedly the photocatalytic degradation of anionic dyes. According to Měštánková et al., this effect was mainly the result of the synergism of photochemical activity between $\mathrm{TiO}_{2}$ and $\mathrm{FeCl}_{3}$ [24]. However, the results of experiments showing that $\mathrm{FeCl}_{3}$ alone did not exhibit the photochemical activity in wastewater and it decreased the photodegradation rate of cationic dyes may indicate other possible mechanism. It should be noted that even more important is the above described process of intensification of sorption of dyes coordinated with $\mathrm{FeCl}_{3}$ onto $\mathrm{TiO}_{2}$ surface [23]. The other reason could be the fact that the addition of $\mathrm{FeCl}_{3}$ and simultaneously decrease of $\mathrm{pH}$ cause agglomeration of suspensions in wastewaters and also increase in stability and photoavailability of the $\mathrm{TiO}_{2}$ used [30].

\section{Conclusions}

Dyeing effluents irradiated in the presence of $\mathrm{FeCl}_{3}$ alone were decolorized, but azo dyes almost completely did not undergo degradation. On the country, the photocatalytic process carried out with $\mathrm{TiO}_{2}$ and $\mathrm{TiO}_{2} / \mathrm{FeCl}_{3}$ as photocatalysts was the effective method of decolorization and dyes photodegradation in the investigated effluents (except samples containing high concentration of very stable azo dye). During the photocatalytic degradation of anionic dyes, a mixture of $\mathrm{TiO}_{2} / \mathrm{FeCl}_{3}$ was more effective while in the case of cationic dyes, more suitable seems to be $\mathrm{TiO}_{2}$ alone.

\section{Acknowledgment}

This work was supported by the Medical University of Silesia (Grant no. KNW-1-043/P/2/0).

\section{References}

[1] R. G. Saratale, G. D. Saratale, J. S. Chang, and S. P. Govindwar, "Decolorization and biodegradation of reactive dyes and dye wastewater by a developed bacterial consortium," Biodegradation, vol. 21, no. 6, pp. 999-1015, 2010. 
[2] T. Robinson, G. McMullan, R. Marchant, and P. Nigam, "Remediation of dyes in textile effluent: a critical review on current treatment technologies with a proposed alternative," Bioresource Technology, vol. 77, no. 3, pp. 247-255, 2001.

[3] J. C. Garcia, J. L. Oliveira, A. E. C. Silva, C. C. Oliveira, J. Nozaki, and N. E. de Souza, "Comparative study of the degradation of real textile effluents by photocatalytic reactions involving $\mathrm{UV} / \mathrm{TiO}_{2} / \mathrm{H}_{2} \mathrm{O}_{2}$ and $\mathrm{UV} / \mathrm{Fe}^{2+} / \mathrm{H}_{2} \mathrm{O}_{2}$ systems," Journal of Hazardous Materials, vol. 147, no. 1-2, pp. 105-110, 2007.

[4] I. M. C. Gonçalves, A. Gomes, R. Brás, M. I. A. Ferra, M. T. P. Amorim, and R. S. Porter, "Biological treatment of effluent containing textile dyes," Coloration Technology, vol. 116, pp. 393397,2000 .

[5] M. Asgher, H. N. Bhatti, S. A. H. Shah, M. J. Asad, and R. L. Legge, "Decolorization potential of mixed microbial consortia for reactive and disperse textile dyestuffs," Biodegradation, vol. 18, no. 3, pp. 311-316, 2007.

[6] B. H. Hameed, A. L. Ahmad, and K. N. A. Latiff, "Adsorption of basic dye (methylene blue) onto activated carbon prepared from rattan sawdust," Dyes and Pigments, vol. 75, no. 1, pp. 143149, 2007.

[7] H. Selcuk, "Decolorization and detoxification of textile wastewater by ozonation and coagulation processes," Dyes and Pigments, vol. 64, no. 3, pp. 217-222, 2005.

[8] A. S. Stasinakis, "Use of selected advanced oxidation processes (AOPs) for wastewater treatment-a mini review," Global NEST Journal, vol. 10, pp. 376-385, 2008.

[9] R. Aplin and T. D. Waite, "Comparison of three advanced oxidation processes for degradation of textile dyes," Water Science and Technology, vol. 42, no. 5-6, pp. 345-354, 2000.

[10] I. Arslan-Alaton, G. Tureli, and T. Olmez-Hanci, "Treatment of azo dye production wastewaters using Photo-Fenton-like advanced oxidation processes: optimization by response surface methodology," Journal of Photochemistry and Photobiology A, vol. 202, no. 2-3, pp. 142-153, 2009.

[11] J. M. Herrmann, "Heterogeneous photocatalysis: state of the art and present applications," Topics in Catalysis, vol. 34, no. 1-4, pp. 49-65, 2005.

[12] I. K. Konstantinou and T. A. Albanis, " $\mathrm{TiO}_{2}$-assisted photocatalytic degradation of azo dyes in aqueous solution: kinetic and mechanistic investigations: a review," Applied Catalysis B, vol. 49, no. 1, pp. 1-14, 2004.

[13] W. Feng and D. Nansheng, "Photochemistry of hydrolytic iron (III) species and photoinduced degradation of organic compounds. A minireview," Chemosphere, vol. 41, no. 8, pp. 1137-1147, 2000.

[14] I. P. Pozdnyakov, Y. A. Sosedova, V. F. Plyusnin et al., "Photodegradation of organic pollutants in aqueous solutions caused by $(\mathrm{OH})_{a q}^{2+}$ photolysis: evidence of $\mathrm{OH}$ radical formation," International Journal of Photoenergy, vol. 6, no. 2, pp. 89-93, 2004.

[15] U. I. Gaya and A. H. Abdullah, "Heterogeneous photocatalytic degradation of organic contaminants over titanium dioxide: a review of fundamentals, progress and problems," Journal of Photochemistry and Photobiology C, vol. 9, no. 1, pp. 1-12, 2008.

[16] O. K. Dalrymple, D. H. Yeh, and M. A. Trotz, "Removing pharmaceuticals and endocrine-disrupting compounds from wastewater by photocatalysis," Journal of Chemical Technology and Biotechnology, vol. 82, no. 2, pp. 121-134, 2007.

[17] R. Rajeswari and S. Kanmani, "A study on degradation of pesticide wastewater by $\mathrm{TiO}_{2}$ photocatalysis," Journal of Scientific and Industrial Research, vol. 68, no. 12, pp. 1063-1067, 2009.
[18] Z. F. Guo, R. X. Ma, and G. J. Li, "Degradation of phenol by nanomaterial $\mathrm{TiO}_{2}$ in wastewater," Chemical Engineering Journal, vol. 119, pp. 55-59, 2006.

[19] C. Jia, Y. Wang, C. Zhang, and Q. Qin, "UV-TiO 2 photocatalytic degradation of landfill leachate," Water, Air, and Soil Pollution, vol. 217, no. 1-4, pp. 375-385, 2011.

[20] V. Sarria, M. Deront, P. Péringer, and C. Pulgarin, "Degradation of a biorecalcitrant dye precursor present in industrial wastewaters by a new integrated iron(III) photoassisted-biological treatment," Applied Catalysis B, vol. 40, no. 3, pp. 231-246, 2003.

[21] L. Poulain, G. Mailhot, P. Wong-Wah-Chung, and M. Bolte, "Photodegradation of chlortoluron sensitised by iron(III) aquacomplexes," Journal of Photochemistry and Photobiology A, vol. 159, no. 1, pp. 81-88, 2003.

[22] C. Catastini, S. Rafqah, G. Mailhot, and M. Sarakha, "Degradation of amitrole by excitation of iron(III) aquacomplexes in aqueous solutions," Journal of Photochemistry and Photobiology A, vol. 162, no. 1, pp. 97-103, 2004.

[23] W. Baran, A. Makowski, and W. Wardas, "The influence of $\mathrm{FeCl}_{3}$ on the photocatalytic degradation of dissolved azo dyes in aqueous $\mathrm{TiO}_{2}$ suspensions," Chemosphere, vol. 53, no. 1, pp. 87-95, 2003.

[24] H. Měštánková, J. Krýsa, J. Jirkovský, G. Mailhot, and M. Bolte, "The influence of $\mathrm{Fe}$ (III) speciation on supported $\mathrm{TiO}_{2}$ efficiency: example of monuron photocatalytic degradation," Applied Catalysis B, vol. 58, pp. 185-191, 2005.

[25] J. Zhang, D. Fu, Q. Peng, L. Deng, and X. Yang, "Fe ${ }^{3+}$-assisted photocatalytic oxidation of sulfamethazine in $\mathrm{TiO}_{2}$ suspended solution," Fresenius Environmental Bulletin, vol. 20, no. 4, pp. 1051-1056, 2011.

[26] I. A. Alaton, I. A. Balcioglu, and D. W. Bahnemann, "Advanced oxidation of a reactive dyebath effluent: Comparison of $\mathrm{O}_{3}$, $\mathrm{H}_{2} \mathrm{O}_{2}$ /UV-C and $\mathrm{TiO}_{2} / \mathrm{UV}$-A processes," Water Research, vol. 36, no. 5, pp. 1143-1154, 2002.

[27] P. A. Pekakis, N. P. Xekoukoulotakis, and D. Mantzavinos, "Treatment of textile dyehouse wastewater by $\mathrm{TiO}_{2}$ photocatalysis," Water Research, vol. 40, no. 6, pp. 1276-1286, 2006.

[28] C. C. Liu, Y. H. Hsieh, P. F. Lai, C. H. Li, and C. L. Kao, "Photodegradation treatment of azo dye wastewater by $\mathrm{UV} / \mathrm{TiO}_{2}$ process," Dyes and Pigments, vol. 68, no. 2-3, pp. 191-195, 2006.

[29] J. C. Garcia, J. I. Simionato, A. E. C. Silva, J. Nozaki, and N. E. de Souza, "Solar photocatalytic degradation of real textile effluents by associated titanium dioxide and hydrogen peroxide," Solar Energy, vol. 83, no. 3, pp. 316-322, 2009.

[30] W. Baran, E. Adamek, and A. Makowski, "The influence of selected parameters on the photocatalytic degradation of azodyes in the presence of $\mathrm{TiO}_{2}$ aqueous suspension," Chemical Engineering Journal, vol. 145, no. 2, pp. 242-248, 2008.

[31] "Methods for Chemical Analysis of Water and Wastes, Chemical Oxygen Demand, Titrimetric Methods 410.1-3," US EPA United States Environmental Protection Agency, Office of Research and Development, Washington, DC, USA, EPA/600/ 4-79/020, pp. 443-451, March 1983, http://nepis.epa.gov/.

[32] W. Baran, A. Makowski, and W. Wardas, "Changes in COD values in aqueous solutions of the selected azo dyes during the photocatalytic degradation process," in Micropollution in the Human Environment, vol. 51, pp. 215-221, Częstochowa University of Technology Publishing House, Częstochowa, Poland, 2003.

[33] W. Baran, J. Sochacka, and W. Wardas, "Toxicity and biodegradability of sulfonamides and products of their photocatalytic 
degradation in aqueous solutions," Chemosphere, vol. 65 , no. 8 , pp. 1295-1299, 2006.

[34] E. Bizani, K. Fytianos, I. Poulios, and V. Tsiridis, "Photocatalytic decolorization and degradation of dye solutions and wastewaters in the presence of titanium dioxide," Journal of Hazardous Materials, vol. 136, no. 1, pp. 85-94, 2006.

[35] C. Lizama, J. Freer, J. Baeza, and H. D. Mansilla, "Optimized photodegradation of reactive blue 19 on $\mathrm{TiO}_{2}$ and $\mathrm{ZnO}$ suspensions," Catalysis Today, vol. 76, no. 2-4, pp. 235-246, 2002.

[36] D. Mantzavinos and E. Psillakis, "Enhancement of biodegradability of industrial wastewaters by chemical oxidation pretreatment," Journal of Chemical Technology and Biotechnology, vol. 79, no. 5, pp. 431-454, 2004. 

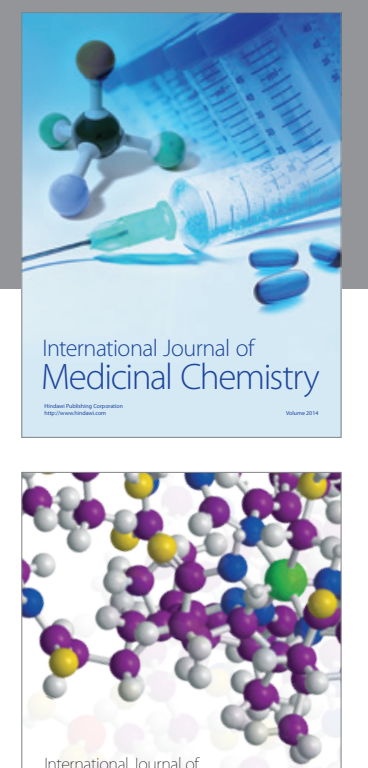

\section{Carbohydrate} Chemistry

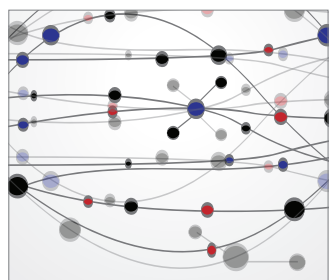

The Scientific World Journal
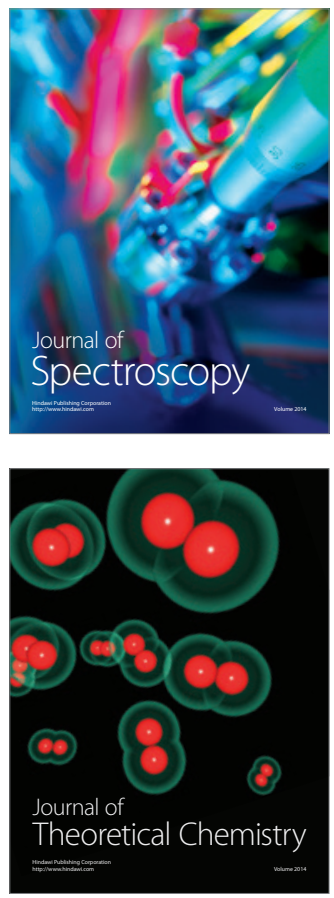
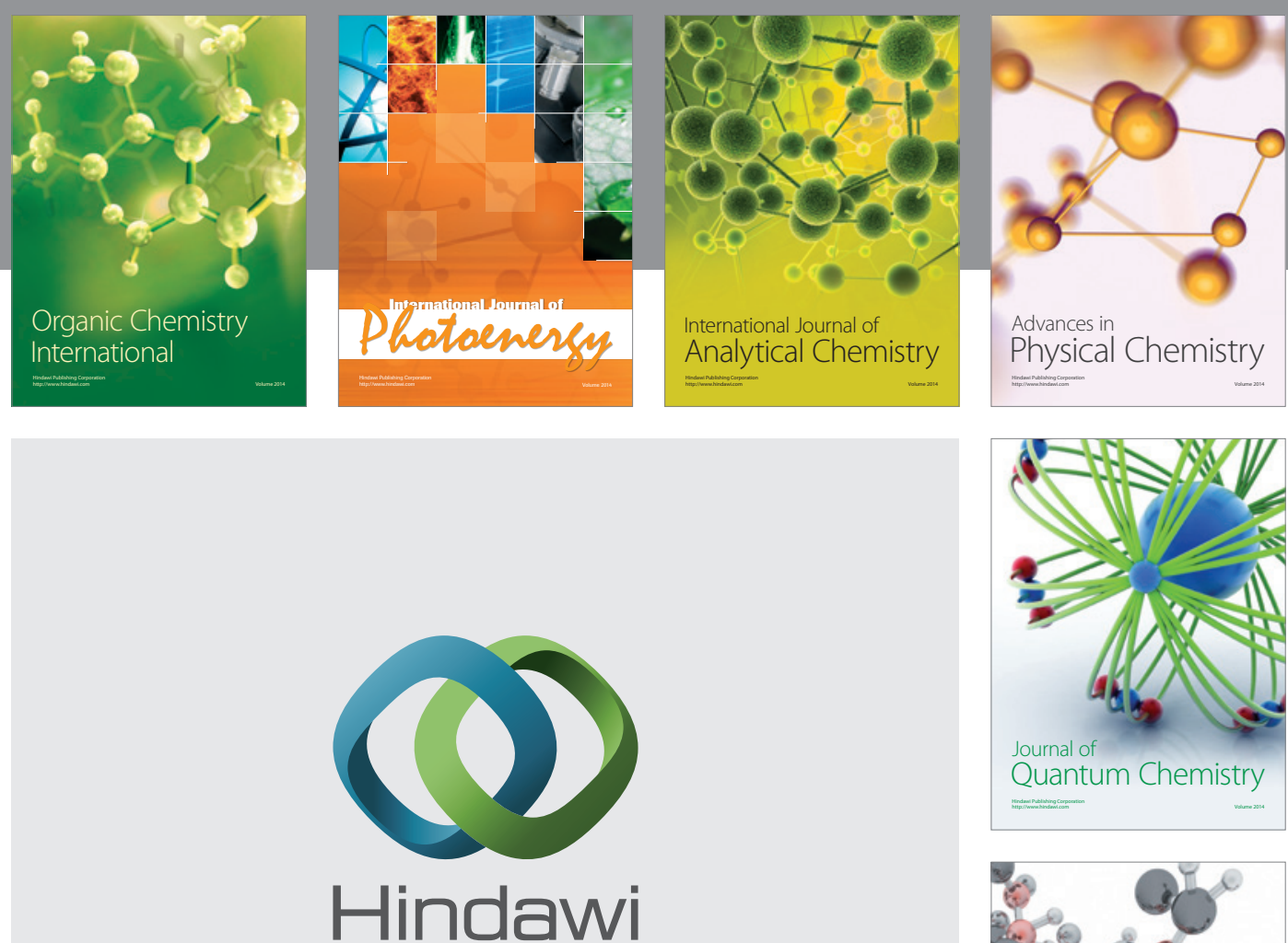

Submit your manuscripts at

http://www.hindawi.com

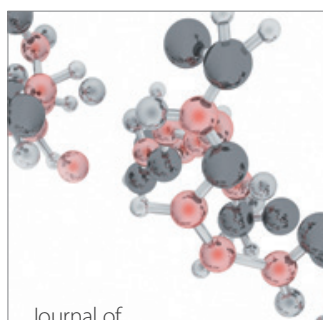

Analytical Methods

in Chemistry

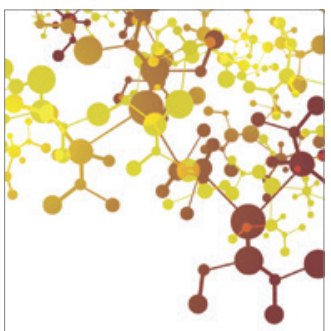

Journal of

Applied Chemistry

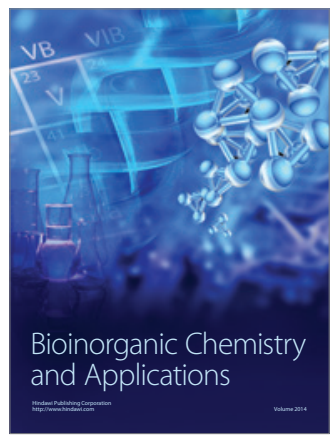

Inorganic Chemistry
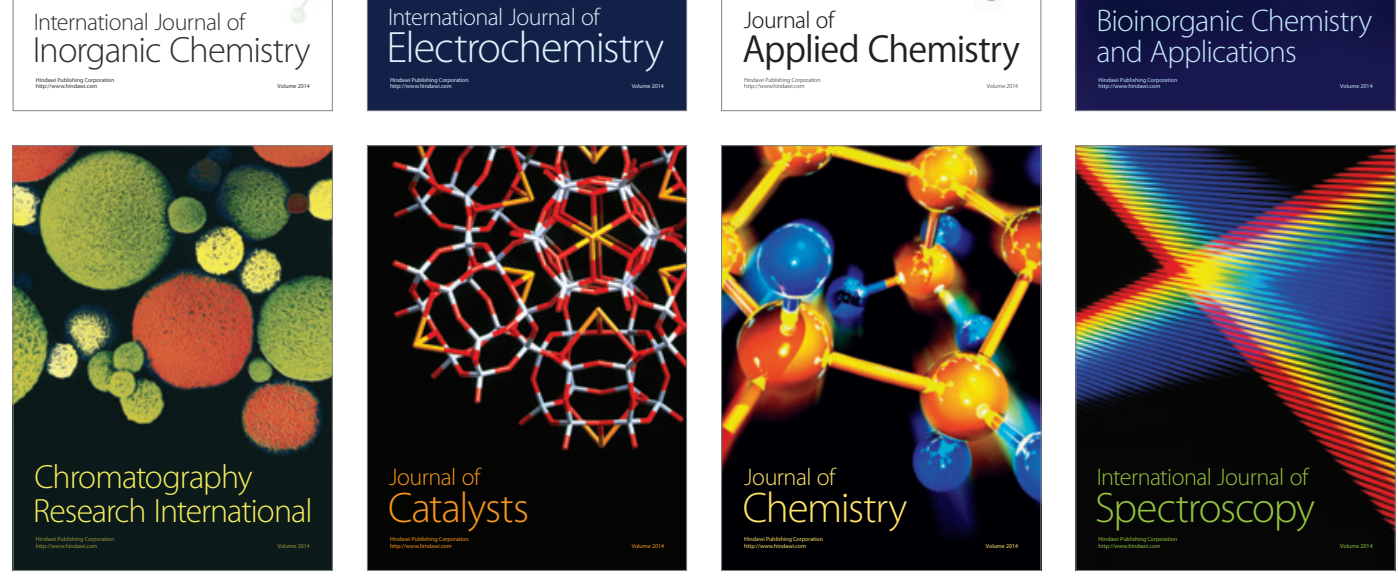